\title{
EDITORIAL COMMENT ON THE SECTION INVITED PAPERS
}

In this issue of the ASTIN Bulletin you find for the first time two invited papers. Under this heading the editors intend to publish papers of a more expository nature, in particular on new scientific developments, which are relevant to our profession. As the title indicates, the authors have been invited to write such a paper.

The two papers in this issue treat the basic mathematical tools in the modern theory of finance. With these publications the ASTIN Bulletin wants to contribute its share to the development of the new section AFIR (Actuarial Approach for Financial Risks), founded by IAA at the International Congress of Helsinki.

The editors of the ASTIN Bulletin would also like to use this opportunity to welcome readers to the AFIR section. 